\title{
Proton transport in KDP-family of ferroelectric materials
}

\author{
AJAY KUMAR, S A HASHMI and SURESH CHANDRA \\ Physics Department, Banaras Hindu University, Varanasi 221005 , India \\ Abstract. Proton transport in potassium difydrogen phosphate (KDP) and ammonium \\ dihydrogen phosphate (ADP) is brichly rewiewed. The experimental results of Wagner's \\ polarization measurcment, coulometry, inltared spectroscopy, transient ionic current measure- \\ ment, the variation of elcctrical cond uctivity with temper ature and electrogravimetric analysis \\ for $\mathrm{KDP}$ and $\mathrm{ADP}$ are reported. $\mathrm{H}^{+}$and $\mathrm{OH}^{-}$ions are ascertained as the mobile ionic \\ species. A new mechatrism for the proton transport in KDP and ADP is suggested: $A$ \\ three-fold rotation of $\mathrm{H}_{2} \mathrm{PO}_{4}^{-}$units aboul any of the axes of $\mathrm{PO}_{4}$ tetrahedra leads to a \\ configuration like $\mathrm{O} \ldots \mathrm{H}_{. .} \mathrm{H}_{\ldots} \mathrm{O}$, the rearrangement of which provides $\mathrm{H} \ldots \mathrm{O} \ldots \mathrm{H}$ bridge that \\ gets electrodissociated on the application of a d.c. electric field.
}

Keywords. Proton transport; KDP-type ferroelectrics; coulonetry; electrogravimetry.

\section{Introduction}

The ferroelectric material polassium dihydrogen phosphate (KDP) and the antiferroelectric material ammonium dihydrogen phosphate (ADP) are well estabkished proton conductors. The motion of structural protons controls both the ferroelectric/ antiferroelectric properties and the proton transport in these materials. KDP and ADP remain in the paraelectric phasc at room temperature with tetragonal $1 \overline{4} 2 \mathrm{~d}$ symmetry (Slater 1941; Ueda 1948; Frazer and Pepinsky 1953; Tenzer et al 1958). Both ADP and KDP have four molecules per unit cell with almost identical phosphate lattice. The phosphate $\left(\mathrm{PO}_{4}\right)$ groups are tetrahedrally attached with four other $\mathrm{PO}_{4}$ groups via hydrogen bonds. On an average, each $\mathrm{PO}_{4}$ group has two protons forming a network of $\mathrm{H}_{2} \mathrm{PO}_{4}^{-}$ions ionically bonded with $\mathrm{K}^{+} / \mathrm{NH}_{4}^{+}$ions. In the case of KDP, only one type of hydrogen bond network exists associated with $\mathrm{PO}_{4}$ group whereas in the case of ADP, two types of hydrogen bond networks are present; one is associated with $\mathrm{PO}_{4}$ group and the other with $\mathrm{NH}_{4}^{+}$ions. Various proton transport mechanisms in KDP and ADP have been suggested earlier invoking the involvement of different types of defects in the hydrogen bond network. These defects are in general the ionization defects and the orientational defects, i.e. L- and D-defects (O'Keeffe and Perrino 1967).

According to Murphy (1964), proton migrates through the hydrogen bond network by alternate interbond and intrabond proton jumps between $\mathrm{H}_{2} \mathrm{PO}_{4}^{-}$units, i.e. Land D-defects migration. Harris and Vella (1973) attributed the L- and D-defects to proton transport in KDP, but considered the additional A-defects (proton vacancies in ammonium lattice) to ADP. Sharon and Kalia (1977) suggested a synchronized rotation of $\mathrm{H}_{2} \mathrm{PO}_{4}^{-}$units around the three-fold axes of $\mathrm{PO}_{4}$ tetrahedra leading to a possible unstable situation like $\mathrm{O}$........... $\mathrm{O}$ between $\mathrm{H}_{2} \mathrm{PO}_{4}^{-}$units and forcing them to revert back to the initial position by bidirectional axial rotation. This to-and-fro movement of the proton can be restricted to a direction by applying a d.c. electrical field across the KDP/ADP sampie.

Our experimental investigations, viz. coulometry, gas chromatography, infrared 
study, transient ionic current measurement, electrical conductivity measurement and elcctrogravimetric analysis (EGA) on KDP and ADP have ied us to propose a mechanism (Chandra and Kumar 1990a, 1991) of proton transport in KDP and ADP.

\section{Experimental}

Experimental studies on KDP and ADP were performed on polycrystalline pellets pressed at $10,000 \mathrm{lbs} / \mathrm{cm}^{2}$.

The ionic transference numbers of KDP and ADP were determined directly by two experiments: (i) Wagner's polarization measurement (Wagner and Wagner 1957) and coulometry (Chandra 1988; Chandra et al 1986a, 1989). In the first measurement, one blocking and one non-blocking electrodes are required. However, in the present case, no suitable blocking or non-blocking electrode could be identified and thereforc a thick silver coating was depositcd as biocking electrode on each of the faces of the KDP/ADP polycrystalline pellet using vacuum evaporation technique. The results obtained, i.e. current vs time plots at fixed potential have been taken as a guide to Wagner's polarization behaviour. This method fails to separate the contributions due to anionic/cationic species in the total translerence number.

In the coulometric experiment, the sample pellet (KDP/ADP) was mounted on a specially designed double-arm electrolysis ceil or coulometer (Chandra et al 1986a, 1989). A constant d.c. current was passed through KDP and ADP pellets. The volume of the gases evolved at the cathode and anode was observed as a function of time. The cathode side gas (hydrogen) was gas chromatographically tested (Tracor Instruments, model 540).

Infrared (IR) spectral studies on the original and electrolyzed KDP/ADI' samples were carried out to identify the electrodissociable groups and the corresponding mobile ionic species. Almost cqual amounts of the original KDP/ADP material and the materials scraped from the anode and cathode sides of the electrolysed KDP/ADP pellet were separately dispersed in the potassium bromide (KBr) matrix in the ratio $\mathrm{L}: 100$. Thin pellets were made and their I R spectra rccorded using a spectrophotometer (Perkin Elmer IR, model 783).

The transicnt ionic current (TIC) was measured on KDP/ADP pellet to determine the number of mobile ionic species and their respective mobilities. Both the faces of the sample pellet were thickly coated with silycr to block the mobile ionic specics. A d.c. voltage was first applied across the sample to polarize it. After some time, the polarity was reversed. Current vs time was monitored. The experimental details were reported earlier (Chandra et al 1988).

The a.c. electrical conductivity was measured in the temperature range $294-490 \mathrm{~K}$ at frequencies ranging $100 \mathrm{~Hz}$ to $100 \mathrm{kHz}$ using a Hewlett-Packard LCR meter (model $4274 \mathrm{~A}$ ). The bulk electrical conductivity at different temperalures was deduced from the complex admittance plots.

EGA is a new analytical technique developed by us to study proton conducting solids (Chandra and Kumar 1989, 1990b). During our experiments with some of the proton conductors (Chandra 1984, 1988, 1989; Chandra et al 1986b, 1989; Chandra and Kumar 1990a), we have noted that gases like $\mathrm{H}_{2}, \mathrm{O}_{2}, \mathrm{NH}_{3}, \mathrm{Cl}_{2}$ etc. are discharged at the respective electrodes on the application of d.c. electric field because of the wehicular transport of ionic species such as $\mathrm{H}^{+}, \mathrm{NH}_{4}^{+}, \mathrm{OH}^{-}, \mathrm{Cl}^{-}$etc resulting in a 
change in the mass of the sample. This change is monitored as a function of time and d.c. electric field in the EGA technique similar to the thermogravimetric analysis (TGA) where the change in mass of the sample is monitored as a function of time and temperature. In the EGA experiment, the sensitive electrical balance of Linseis TGA/DTA unit (TYP 2045) fitted with a special EGA sample holder (see figure 6a) was used. Metallic grid/mesh electrodes were fixed to both laces of KDP pelfet to allow gas evolution (if any) on electrodissociation. This sample pejtet was then mounted on the EGA sample holder. A fixed voltage was applied across the sample and the change in mass was monitored as a function of time. The experimental details were discussed earlier (Chandra and Kumar 1989, 1990b).

\section{Results and discussion}

\section{I Transference number}

3.1a Wagner's polarization measurement: Wagner's polarization curves for KDP and ADP are shown in figure 1. The total ionic transference numbers of KDP and ADP calculated from these curves are 0.98 and 0.99 respectively. This implies that both KDP and ADP are essentially ionic conductors.

3.1b Coulometry: On passing a constant d.c. current through KDP and ADP pellets, gases were evolved at both the cathode and anode. Figure 2 shows the plots

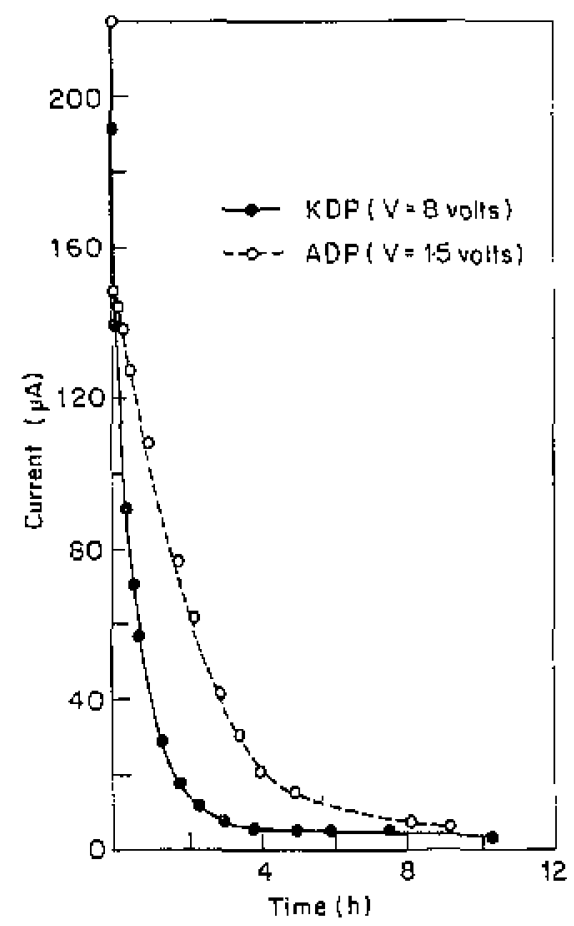

Figure 1. Wagner's polarization plots for KDP and ADP poiycrystalline peliets. 


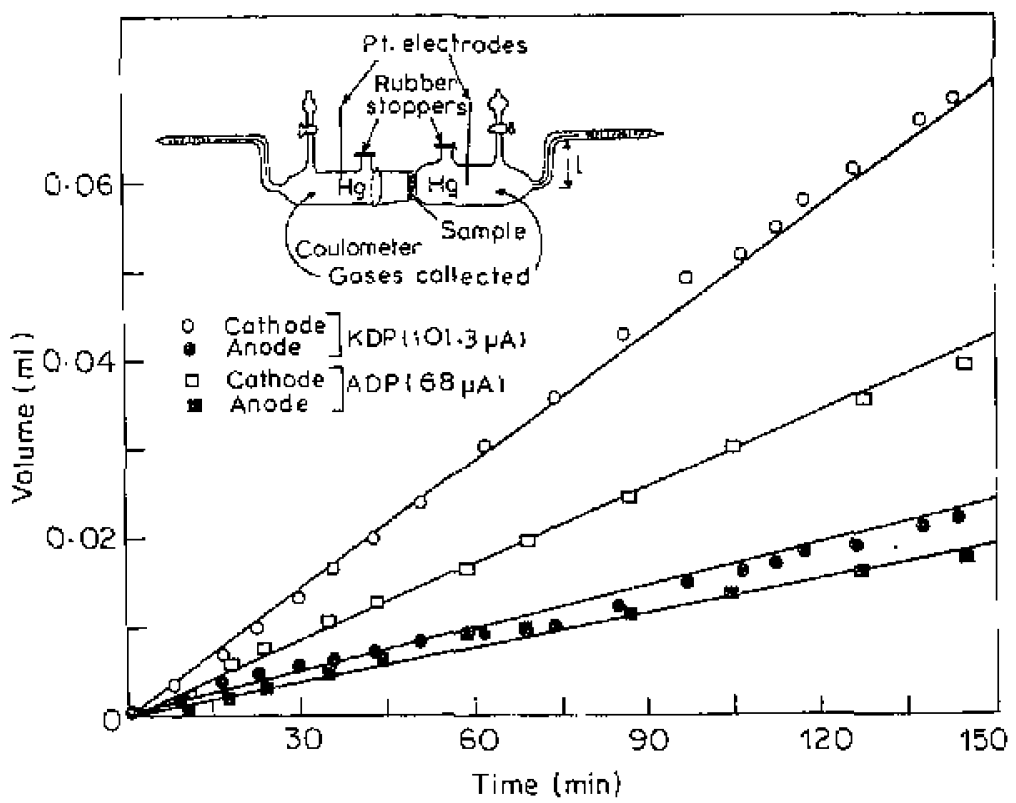

Figure 2. Volumes of the evolved gases observed in the coulometer as a function of time for KDP and ADP.

Table I. Teansicronce numbers for $\mathrm{H}^{\prime}$ and $\mathrm{OH}^{-}$ions.

\begin{tabular}{|c|c|c|c|}
\hline Matcrials & $t_{\mathrm{H}^{*}}$ & $t_{\mathrm{OH}^{-}}$ & Total trangference number \\
\hline $\mathrm{KDP}$ & 064 & $0-16$ & 0.80 \\
\hline ADE & 0.54 & 0.16 & 0.70 \\
\hline
\end{tabular}

of evolved volume of gases for KDP and ADP. The cathode side gas was gas-chromatographically tested and found to be hydrogen. The anode side gas (supposed to be $\mathrm{O}_{2}+\mathrm{H}_{2} \mathrm{O}$ ) could not be tested due to lack of lacility.

The evolution of gases at both the electrodes on the application of d.c. electrical field across KDP and ADP samples suggests the possible electrodissociation of $\mathrm{H} \ldots \mathrm{O} \ldots \mathrm{F}$ bridges formed due to the rotation of $\mathrm{H}_{2} \mathrm{PO}_{4}^{-}$units about the three-fold axes of $\mathrm{PO}_{4}$ tetrahedra generating $\mathrm{H}^{+}$and $\mathrm{OH}^{-}$as the mobile ionic species according to the following reactions (Chandra and Kumar 1991):

$$
\begin{aligned}
& 4 \mathrm{H}_{2} \mathrm{O} \rightarrow 4 \mathrm{H}^{+}+4 \mathrm{OH}^{-}, \\
& 4 \mathrm{H}^{+}+4 \mathrm{e}^{-} \rightarrow 2 \mathrm{H}_{2} \quad \text { (at cathode), } \\
& 4 \mathrm{OH}^{-} \rightarrow 2 \mathrm{H}_{2} \mathrm{O}+\mathrm{O}_{2}+4 \mathrm{e}^{-} \text {(at anode). }
\end{aligned}
$$

The transference numbers evaluated for $\mathrm{H}^{+}$and $\mathrm{OH}^{-}$from the observed volumes of evolved gases can be summarized as given in table 1 , where $t_{\mathrm{H}^{+}}$and $t_{\mathrm{OH}^{-}}$are the transference numbers of $\mathrm{H}^{+}$and $\mathrm{OH}^{-}$ions respectively. We expect the total transference number $\left(t_{i}\right)$ to be less than 1 eyen if the total transference is by ionic transport, because the actual volume of gases measured during coulometric experiment would be less than the evolved gases due to the loss for various reasons like adsorption 
of gases in mercury of the coulometer, possibility of small leakage, electrode reaction like $\mathrm{Hg}^{+}+1 / 2 \mathrm{O}_{2} \rightarrow \mathrm{HgO}$ etc.

\subsection{IR-spectral studies}

The IR spectra of the original as well as the electrolyzed KDP and ADP samples are shown in figure 3 . The salient changes in the IR-spectra because of ion migration under d.c. electrical field are as follows:

(I) KDP: (a) Disappearance of the peaks at $3560,3240,1730,1645$ and $820 \mathrm{~cm}^{-1}$ after clectrodissociation. These have been attributed to electrolysis of $\mathrm{H} . . . \mathrm{O} . . . \mathrm{H}$ bridges formed due to rotation of $\mathrm{H}_{2} \mathrm{PO}_{4}^{-}$units as shown in figure 7. (b) Appearance of a strong peak at $930 \mathrm{~cm}^{-1}$ supcrimposed over a broad $950 \mathrm{~cm}^{-1}$ peak which has been assigned to the growth of symmetric $\mathrm{P}-\mathrm{O}-\mathrm{P}$ bond after electrodissociation (see figure 7). (c) Appearance of a new peak at $535 \mathrm{~cm}^{-1}$ after electrodissociation. This has also been assigned to the symmetric $\mathrm{P}-\mathrm{O}-\mathrm{P}$ bond formed by the process illustrated in figure 7 (discussed later). (d) Disappearance of the peak at $485 \mathrm{~cm}^{-1}$ after electrodissociation. It is reported (Blinc et al 1968) that in KDP at higher temperatures $\mathrm{H}_{2} \mathrm{PO}_{4}$ unit rotates and acquires such a configuration that intrabond proton tunnelling between $\mathrm{H}_{2} \mathrm{PO}_{4}^{-}$units ceases and the corresponding peak $\left(450 \mathrm{~cm}^{-1}\right)$ becomes weak. In the present case, it seems that a similar situation is created on the application of d.c. field through a process of $\mathrm{H}_{2} \mathrm{PO}_{4}^{-}$group rotation and subsequent alectrodissociation (as shown in ligure 7 ) resulting in the disappearance of the $485 \mathrm{~cm}^{-1}$ peak.

(II) ADP: (a) Disappearance of peak at $1650 \mathrm{~cm}^{-1}$ after electrodissociation of H... O...H bridges as discussed for KDP. (b) Appearance of a new peak at $525 \mathrm{~cm}^{-1}$

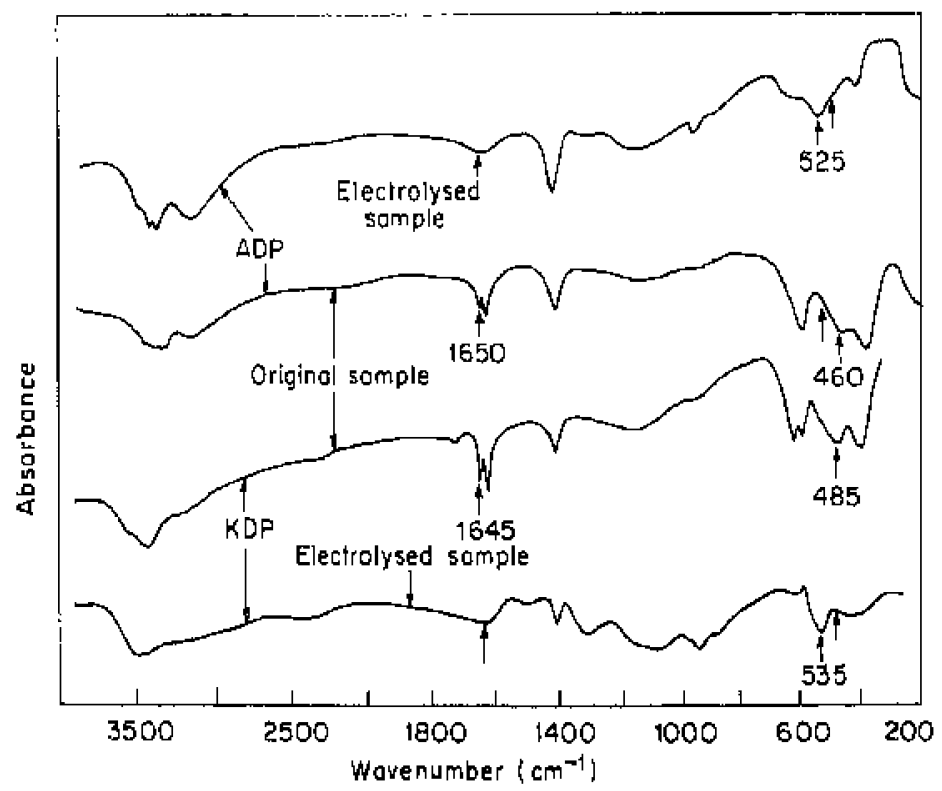

Figure 3. IR-spectra of the original and the electrolyzed samples of KDP and ADP polyctystalline materials. 


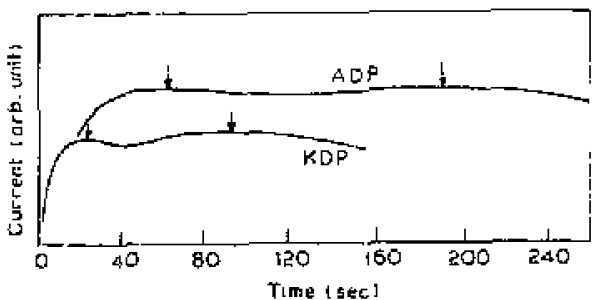

Figure 4. TIC plots of KDP and ADP polycrystalline pellets.

Table 2. TIC results for KDP and ADP.

\begin{tabular}{lcc}
\hline Materiafs & KDP & ADP \\
\hline $\begin{array}{l}\text { No of peaks } \\
\text { Possibje mobile species }\end{array}$ & $\begin{array}{c}2 \\
\mathrm{H}^{+} \text {and } \mathrm{OH}^{-} \\
\mu_{\mathrm{H}^{+}}=3 \cdot 6 \times 10^{-5} \\
\mu_{\mathrm{OH}^{-}}=9 \cdot 3 \times 10^{-6}\end{array}$ & $\begin{array}{c}\mathrm{H}^{+} \text {and } \mathrm{OH}^{-} \\
1.34 \times 10^{-4} \mathrm{~cm}^{2} / \mathrm{s} \\
\text { Mobility values }\end{array}$ \\
\hline
\end{tabular}

after electrodissociation corresponding to the symmetric $\mathrm{P}-\mathrm{O}-\mathrm{P}$ bond formed by the process shown in figure 7 (discussed later). (c) Disappearance of $460 \mathrm{~cm}^{-1}$ peak after electrodissociation because the intrabond proton tunnelling between $\mathrm{H}_{2} \mathrm{PO}_{4}$ units possibly ceases on the application of d.c. electric field as discussed for KDP in (d).

\subsection{Trunsient ionic current measurement (TIC) for mobility}

In this experiment, the sample was first polarized by applying a fixed d.c. potential. After some time, the polarity was reversed. Current vs time was monitored. The number of peaks provides the number of mobile ionic species. The time taken for peaking is related to the mobility (Chandra et al 1988). The TIC plots for KDP and ADP are shown in figure 4 . The results are summarized in table 2 , where $\mu_{\mathbf{H}}$, and $\mu_{\mathrm{OH}^{-}}$are the mobilities of $\mathrm{H}^{+}$and $\mathrm{OH}^{-}$ions, respectively.

\subsection{Electrical conductivity}

Figure 5 shows the tempcrature dependence of bulk electrical conductivity $(\sigma)$ of KDP and ADP in the ambient atmosphere. The bulk conductivity was evaluated using the complex impedance spectroscopy technique. The initial decrease in the value of bulk conductivity of KDP and ADP with increase in temperature is an artifact because of the loss of surface adsorbed water (Chandra and Kumar 1990, 1991). The onset of a dip in $\mathrm{KDP}$ after $423 \mathrm{~K}$ has been assigned to the structural change from tetragonal to monoclinic (Chandra and Kumar 1991).

\subsection{Electrogravimetric analysis}

The EGA experiment on KDP polycrystaline peilet was carried out in vacuum to avoid any confusion from changes in mass because of varying surface hydration due 


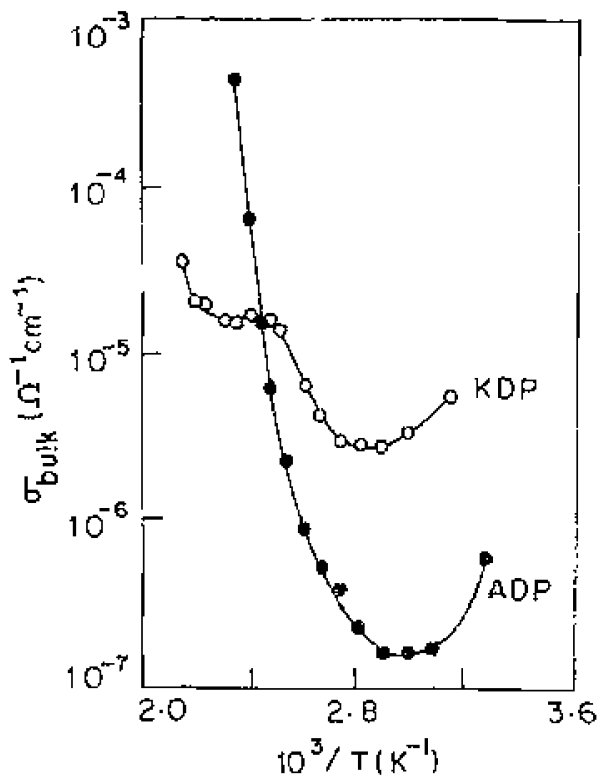

Figure 5. Yatiation of the bulk electrical conductivity of KDP and ADP polycrystallinc pellets in the ambjent atmosphere.

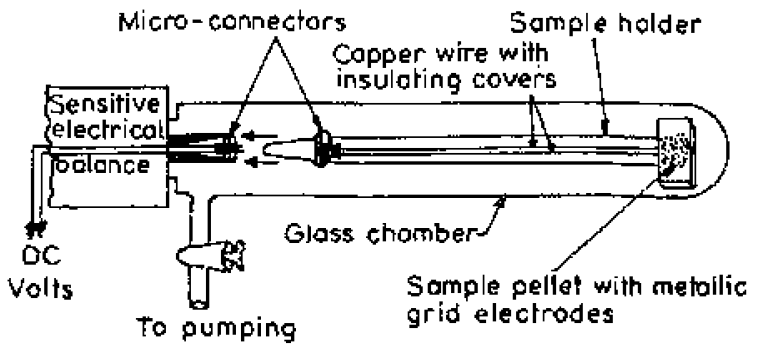

(0)

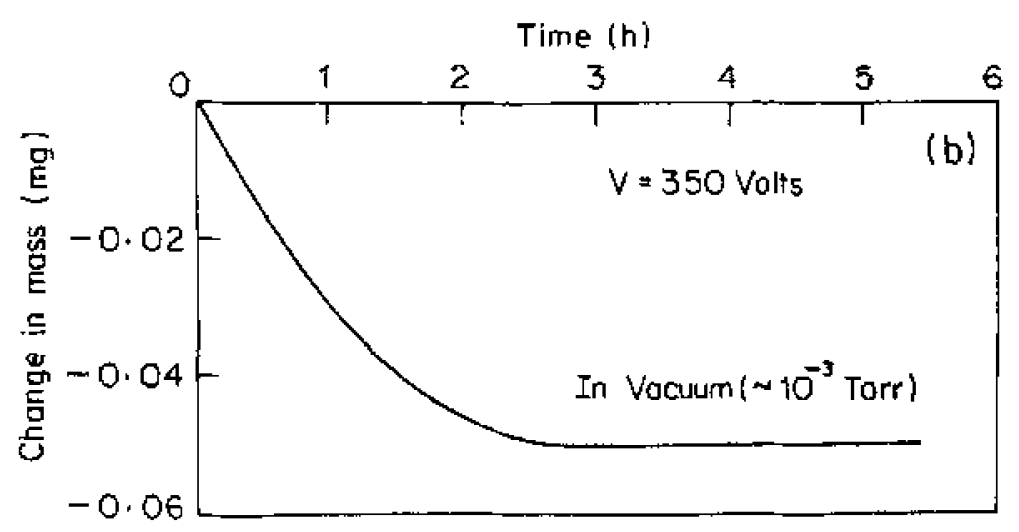

(b)

Figure 6. (a) Schematic diagram of the sample holder used for EGA experiment, and (b) Joss in mass of the KDP sample (initial mass $\approx 220 \mathrm{mg}$ ). 


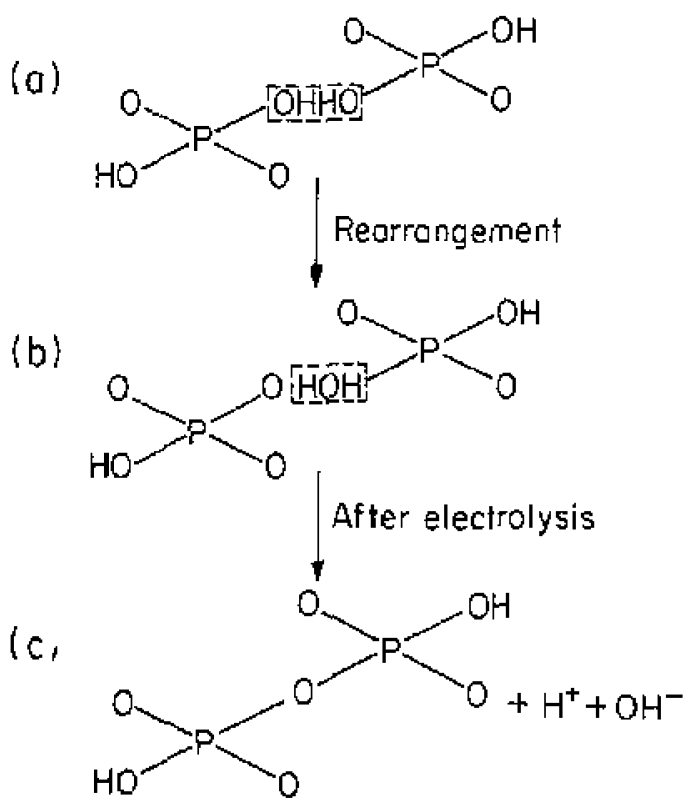

Figure 7. Schematic illustration of the proton transport mechanism in KDP and ADP.

to minor changes in ambient humidity. Figure $6 \mathrm{~b}$ shows the EGA results of KDP in vacuum. On the application of 350 volts across the sample, the mass of the sample decreases and ultimately equilibrates after nearly $2.5 \mathrm{~h}$ following the electrolysis of H.......H bridges (formed due to the process shown in figure 7) producing $\mathrm{H}^{+}$and $\mathrm{OH}^{-}$as the mobile ionic species.

On the basis of the above experimental resules, the suggested proton transport mechanism for KDP and ADP is: A three-fold rotation of $\mathrm{H}_{2} \mathrm{PO}_{4}$ units about any of the axes of $\mathrm{PO}_{4}$ tetrahedra results in a situation like O...H...H...O (the D-defect) as shown in figure $7 \mathrm{a}$. It rearranges itself in an unstable configuration as $\mathrm{H} . . . \mathrm{O} . . . \mathrm{H} . . . \mathrm{O}$ (figure 7b) which ultimately gets electrodissociated on the application of the d.c. electrical Field generating $\mathrm{H}^{+}$and $\mathrm{OH}^{-}$as the mobile ionic species and as a result a $\mathrm{P}-\mathrm{O}-\mathrm{P}$ bond is formed between the electrodissociated $\mathrm{H}_{2} \mathrm{PO}_{4}^{-}$units as illustrated in figure $7 \mathrm{c}$.

\section{References}

Bline R, Dimic V, Lahajnar G, Stepisnic J, Zumer S. Vene N and Hadzi D 1968 J. Chem. Phys. 44996 Chandra $\$ 1984$ Mater, Sci. Forwm 1153

Chandra $S 1988$ in Solid state ionic devices (eds) B V R Chowdari and S Radhakrishna (Singapore: World Scientific) p. 265

Chandra S 1989 in Superionic solds and solid electrolytes - Reeent trends (eds) A L Laskar and S Chandra (New York: Academic Press) p. 185

Charzdra S and Kumar A 5989 Mater. Res. Bull. 2441 "

Chandra S and Kumar A 1990a Solid State Ionics 40/41 863

Chandra $S$ and Kumar A 1990 b Solid State Ionics 40/41 255

Chandra 5 and Kumar A 1991 J. Phys.: Condens. Matter 3527

Chandra S, Singh N and Singh B 1986a Solid State Commum, 57519

Chandra S, Singh N and Hashmi S A 19B6b Proc. Ihdïrn Nat. Sci. Acad. 52338 
Chandry. S, Tolpadi S K and Hashmi S A 1988 Solla State lonics 28-30 651

Chandra $S_{1}$ Talpadi S K and Hashmi S A 1989 J. Phys, Condens. Matter t 9101

Frazer B C and Pepisski R 1953 Acta Crysiallogr. 6273

Harris L B and Vella G T 1973 J. Chem. Phys. 584550

Murphy E J 1964 J. Appl. Phips. 352609

O'Keeffe M and Perrine C T 1967 J. Phys. Chert. Solids 28211

Sharon M and Kalja A K $1977 \mathrm{~J}$. Sold State Chem, 21171

Slater J C $1941 \mathrm{~J}$. Chem. Phys. 916

Tenzer L, Frazer B C and Pepinski R 1958 Acta Crystallogr. $11 \$ 05$

Ueda R 1948 J. Pligs. Soc. Jpn 3669

Wagner I B and Wagner C 1957 J. Chem. Phys. 261597 